\title{
New Modified Ratio Estimator for Estimation of Population Mean when Median of the Auxiliary Variable is Known
}

\author{
J. Subramani \\ Department of Statistics \\ Ramanujan School of Mathematical Sciences \\ Pondicherry University \\ R V Nagar, Kalapet, Puducherry - 605014 \\ drjsubramani@yahoo.co.in \\ G. Kumarapandiyan \\ Department of Statistics \\ Ramanujan School of Mathematical Sciences \\ Pondicherry University \\ R V Nagar, Kalapet, Puducherry - 605014 \\ kumarstat88@gmail.com
}

\begin{abstract}
The present paper deals with a modified ratio estimator for estimation of population mean of the study variable when the population median of the auxiliary variable is known. The bias and mean squared error of the proposed estimator are derived and are compared with that of existing modified ratio estimators for certain known populations. Further we have also derived the conditions for which the proposed estimator performs better than the existing modified ratio estimators. From the numerical study it is also observed that the proposed modified ratio estimator performs better than the existing modified ratio estimators for certain known populations.
\end{abstract}

Keywords: Mean squared error, Modified Ratio estimator, Natural Populations, Simple random sampling.

AMS classification: 62 D05.

\section{Introduction}

Consider a finite population $\mathrm{U}=\left\{\mathrm{U}_{1}, \mathrm{U}_{2}, \ldots, \mathrm{U}_{\mathrm{N}}\right\}$ of $N$ distinct and identifiable units. Let $Y$ be a real variable with value $Y_{i}$ measured on $\mathrm{U}_{\mathrm{i}}, \mathrm{i}=1,2,3, \ldots, \mathrm{N}$ giving a vector $\mathrm{Y}=\left\{\mathrm{Y}_{1}, \mathrm{Y}_{2}, \ldots, \mathrm{Y}_{\mathrm{N}}\right\}$. The problem is to estimate the population mean $\overline{\mathrm{Y}}=\frac{1}{\mathrm{~N}} \sum_{\mathrm{i}=1}^{\mathrm{N}} \mathrm{Y}_{\mathrm{i}}$ on the basis of a random sample selected from the population $U$. When there is no additional information on the auxiliary variable available, the simplest estimator of population mean is the simple random sample mean without replacement. However if an auxiliary variable $\mathrm{X}$ closely related to the study variable $\mathrm{Y}$ is available then one can improve the performance of the estimator of the study variable. That is, when the population mean, $\bar{X}$ of the auxiliary variable $\mathrm{X}$ is known, a number of estimators such as ratio, product and linear regression estimators are proposed in the literature. Among these estimators the ratio estimator and its modifications are widely used for the estimation of the mean of the study variable. 
Before discussing further about the modified ratio estimators and the proposed modified ratio estimator the notations to be used in this paper are described below:

- $\mathrm{N}$ - Population size

- $\mathrm{n}$ - Sample size

- $\mathrm{f}=\mathrm{n} / \mathrm{N}$, Sampling fraction

- $\mathrm{Y}$ - Study variable

- $\mathrm{X}$ - Auxiliary variable

- $\bar{X}, \bar{Y}-$ Population means

- $\mathrm{x}, \mathrm{y}$ - Sample totals

- $\overline{\mathrm{x}}, \overline{\mathrm{y}}-$ Sample means

- $\mathrm{S}_{\mathrm{X}}, \mathrm{S}_{\mathrm{y}}-$ Population standard deviations

- $\mathrm{C}_{\mathrm{X}}, \mathrm{C}_{\mathrm{y}}-$ Coefficient of variations

- $\rho-$ Coefficient of correlation

- $\beta_{1}=\frac{\mathrm{N} \sum_{\mathrm{i}=1}^{\mathrm{N}}\left(\mathrm{X}_{\mathrm{i}}-\overline{\mathrm{X}}\right)^{3}}{(\mathrm{~N}-1)(\mathrm{N}-2) \mathrm{S}^{3}}$, Coefficient of skewness of the auxiliary variable

- $\beta_{2}=\frac{\mathrm{N}(\mathrm{N}+1) \sum_{\mathrm{i}=1}^{\mathrm{N}}\left(\mathrm{X}_{\mathrm{i}}-\overline{\mathrm{X}}\right)^{4}}{(\mathrm{~N}-1)(\mathrm{N}-2)(\mathrm{N}-3) \mathrm{S}^{4}}-\frac{3(\mathrm{~N}-1)^{2}}{(\mathrm{~N}-2)(\mathrm{N}-3)}$, Coefficient of kurtosis of the auxiliary variable

- $B()-$. Bias of the estimator

- $\operatorname{MSE}($.$) - Mean squared error of the estimator$

- $\widehat{\mathrm{Y}}\left(\widehat{\overline{\mathrm{Y}}}_{\mathrm{p}}\right)$ - Existing (proposed) modified ratio estimator of $\overline{\mathrm{Y}}$

The classical Ratio estimator for the population mean $\bar{Y}$ of the study variable $Y$ is defined as $\quad \widehat{\overline{\mathrm{Y}}}_{\mathrm{R}}=\frac{\overline{\mathrm{y}}}{\overline{\mathrm{x}}} \overline{\mathrm{X}}=\widehat{\mathrm{R}} \overline{\mathrm{X}}$

where $\widehat{R}=\frac{\bar{y}}{\bar{x}}=\frac{y}{x}$ is the estimate of $R=\frac{\bar{Y}}{\bar{X}}=\frac{Y}{X}$.

The Ratio estimator given in (1.1) is used to improve the precision of the estimate of the population mean compared to simple random sampling when there exists a positive correlation between $\mathrm{X}$ and $\mathrm{Y}$. Further improvements are also achieved on the classical ratio estimator by introducing a large number of modified ratio estimators with the use of known parameters like, Co-efficient of Variation, Co-efficient of Kurtosis, Co-efficient of Skewness and Population Correlation Coefficient. A list of modified ratio estimators given in Table 1.1 is to be used for assessing the performance of the proposed estimator. It is to be noted that "the existing modified ratio estimators" means the list of modified ratio estimators given in Table 1.1 unless otherwise stated. It does not mean the entire list of modified ratio estimators available in the literature. For a more detailed discussion on the ratio estimator and its modifications one may refer to Cochran (1977), Kadilar and 
Cingi (2004, 2006), Koyuncu and Kadilar (2009), Murthy (1967), Prasad (1989), Rao (1991), Singh (2003), Singh and Tailor (2003, 2005), Singh et.al (2004), Sisodia and Dwivedi (1981), Upadhyaya and Singh (1999), Yan and Tian (2010) and the references cited there in. The existing modified ratio estimators together with their biases mean squared errors and the required constants to compute the estimators and their mean squared errors are presented in the table given below:

Table 1.1: Existing modified ratio type estimators with their biases and mean squared errors

\begin{tabular}{|c|c|c|c|}
\hline Estimator & Bias B(.) & Mean squared errors MSE(.) & Constants $\theta_{\mathrm{i}}$ or $\mathrm{R}_{\mathrm{i}}$ \\
\hline $\begin{array}{l}\widehat{\bar{Y}}_{1}=\bar{y}\left[\frac{\bar{X}+C_{x}}{\bar{x}+C_{x}}\right] \\
\text { Sisodia and Dwivedi [13] }\end{array}$ & $\begin{array}{l}\frac{(1-f)}{n} \bar{Y}\left(\theta_{1}^{2} C_{x}^{2}\right. \\
\left.-\theta_{1} C_{x} C_{y} \rho\right)\end{array}$ & $\frac{(1-f)}{n} \bar{Y}^{2}\left(C_{y}^{2}+\theta_{1}^{2} C_{x}^{2}-2 \theta_{1} C_{x} C_{y} \rho\right)$ & $\theta_{1}=\frac{\bar{X}}{\bar{X}+C_{x}}$ \\
\hline $\begin{array}{l}\widehat{\mathrm{Y}}_{2}=\overline{\mathrm{y}}\left[\frac{\overline{\mathrm{X}}+\beta_{2}}{\overline{\mathrm{X}}+\beta_{2}}\right] \\
\text { Singh et al. [11] }\end{array}$ & $\begin{array}{l}\frac{(1-f)}{n} \bar{Y}\left(\theta_{2}^{2} C_{x}^{2}\right. \\
\left.-\theta_{2} C_{x} C_{y} \rho\right)\end{array}$ & $\frac{(1-f)}{n} \bar{Y}^{2}\left(C_{y}^{2}+\theta_{2}^{2} C_{x}^{2}-2 \theta_{2} C_{x} C_{y} \rho\right)$ & $\theta_{2}=\frac{\bar{X}}{\bar{X}+\beta_{2}}$ \\
\hline $\begin{array}{l}\widehat{\mathrm{Y}}_{3}=\overline{\mathrm{y}}\left[\frac{\overline{\mathrm{X}}+\beta_{1}}{\overline{\mathrm{x}}+\beta_{1}}\right] \\
\text { Yan and Tian [15] }\end{array}$ & $\begin{array}{l}\frac{(1-f)}{n} \bar{Y}\left(\theta_{3}^{2} C_{x}^{2}\right. \\
\left.-\theta_{3} C_{x} C_{y} \rho\right)\end{array}$ & $\frac{(1-f)}{n} \bar{Y}^{2}\left(C_{y}^{2}+\theta_{3}^{2} C_{x}^{2}-2 \theta_{3} C_{x} C_{y} \rho\right)$ & $\theta_{3}=\frac{\bar{X}}{\bar{X}+\beta_{1}}$ \\
\hline $\begin{array}{l}\widehat{\mathrm{Y}}_{4}=\overline{\mathrm{y}}\left[\frac{\overline{\mathrm{X}}+\rho}{\overline{\mathrm{X}}+\rho}\right] \\
\text { Singh and Tailor [10] }\end{array}$ & $\begin{array}{l}\frac{(1-f)}{n} \bar{Y}\left(\theta_{4}^{2} C_{x}^{2}\right. \\
\left.-\theta_{4} C_{x} C_{y} \rho\right)\end{array}$ & $\frac{(1-f)}{n} \bar{Y}^{2}\left(C_{y}^{2}+\theta_{4}^{2} C_{x}^{2}-2 \theta_{4} C_{x} C_{y} \rho\right)$ & $\theta_{4}=\frac{\bar{X}}{\bar{X}+\rho}$ \\
\hline $\begin{array}{l}\widehat{\mathrm{Y}}_{5}=\overline{\mathrm{y}}\left[\frac{\overline{\mathrm{X}} \mathrm{C}_{\mathrm{x}}+\beta_{2}}{\overline{\mathrm{x}} C_{\mathrm{x}}+\beta_{2}}\right] \\
\text { Upadhyaya and Singh [14] }\end{array}$ & $\begin{array}{l}\frac{(1-f)}{n} \bar{Y}\left(\theta_{5}^{2} C_{x}^{2}\right. \\
\left.-\theta_{5} C_{x} C_{y} \rho\right)\end{array}$ & $\frac{(1-f)}{n} \bar{Y}^{2}\left(C_{y}^{2}+\theta_{5}^{2} C_{x}^{2}-2 \theta_{5} C_{x} C_{y} \rho\right)$ & $\theta_{5}=\frac{\overline{\mathrm{X}} C_{\mathrm{x}}}{\overline{\mathrm{X}} \mathrm{C}_{\mathrm{x}}+\beta_{2}}$ \\
\hline $\begin{array}{l}\widehat{\mathrm{Y}}_{6}=\frac{\overline{\mathrm{y}}+\mathrm{b}(\overline{\mathrm{X}}-\overline{\mathrm{x}})}{\overline{\mathrm{X}}} \overline{\mathrm{X}} \\
\text { Kadilar and Cingi [2] }\end{array}$ & $\frac{(1-f)}{n} \frac{S_{x}^{2}}{\bar{Y}} R_{6}^{2}$ & $\frac{(1-f)}{n}\left(R_{6}^{2} S_{x}^{2}+S_{y}^{2}\left(1-\rho^{2}\right)\right)$ & $\mathrm{R}_{6}=\frac{\overline{\mathrm{Y}}}{\overline{\mathrm{X}}}$ \\
\hline $\begin{array}{l}\widehat{\mathrm{Y}}_{7}=\frac{\overline{\mathrm{y}}+\mathrm{b}(\overline{\mathrm{X}}-\overline{\mathrm{x}})}{\left(\overline{\mathrm{x}}+\mathrm{C}_{\mathrm{x}}\right)}\left(\overline{\mathrm{X}}+\mathrm{C}_{\mathrm{x}}\right) \\
\text { Kadilar and Cingi [2] }\end{array}$ & $\frac{(1-f)}{n} \frac{S_{x}^{2}}{\bar{Y}} R_{7}^{2}$ & $\frac{(1-f)}{n}\left(R_{7}^{2} S_{x}^{2}+S_{y}^{2}\left(1-\rho^{2}\right)\right)$ & $R_{7}=\frac{\bar{Y}}{\bar{X}+C_{x}}$ \\
\hline $\begin{array}{l}\widehat{\mathrm{Y}}_{8}=\frac{\overline{\mathrm{y}}+\mathrm{b}(\overline{\mathrm{X}}-\overline{\mathrm{x}})}{\left(\overline{\mathrm{x}}+\beta_{2}\right)}\left(\overline{\mathrm{X}}+\beta_{2}\right) \\
\text { Kadilar and Cingi [2] }\end{array}$ & $\frac{(1-f)}{n} \frac{S_{x}^{2}}{\bar{Y}} R_{8}^{2}$ & $\frac{(1-f)}{n}\left(R_{8}^{2} S_{x}^{2}+S_{y}^{2}\left(1-\rho^{2}\right)\right)$ & $R_{8}=\frac{\bar{Y}}{\bar{X}+\beta_{2}}$ \\
\hline $\begin{array}{l}\widehat{\overline{\mathrm{Y}}}_{9}=\frac{\overline{\mathrm{y}}+\mathrm{b}(\overline{\mathrm{X}}-\overline{\mathrm{x}})}{\left(\overline{\mathrm{x}} \mathrm{C}_{\mathrm{x}}+\beta_{2}\right)}\left(\overline{\mathrm{X}} \mathrm{C}_{\mathrm{x}}+\beta_{2}\right) \\
\text { Kadilar and Cingi [2] }\end{array}$ & $\frac{(1-f)}{n} \frac{S_{x}^{2}}{\bar{Y}} R_{9}^{2}$ & $\frac{(1-f)}{n}\left(R_{9}^{2} S_{x}^{2}+S_{y}^{2}\left(1-\rho^{2}\right)\right)$ & $\mathrm{R}_{9}=\frac{\overline{\mathrm{Y}} \mathrm{C}_{\mathrm{x}}}{\overline{\mathrm{X}} \mathrm{C}_{\mathrm{x}}+\beta_{2}}$ \\
\hline $\begin{array}{l}\widehat{\mathrm{Y}}_{10}=\frac{\overline{\mathrm{y}}+\mathrm{b}(\overline{\mathrm{X}}-\overline{\mathrm{x}})}{\left(\overline{\mathrm{x}}+\beta_{1}\right)}\left(\overline{\mathrm{X}}+\beta_{1}\right) \\
\text { Yan and Tian }[15]\end{array}$ & $\frac{(1-f)}{n} \frac{S_{x}^{2}}{\bar{Y}} R_{10}^{2}$ & $\frac{(1-f)}{n}\left(R_{10}^{2} S_{x}^{2}+S_{y}^{2}\left(1-\rho^{2}\right)\right)$ & $\mathrm{R}_{10}=\frac{\overline{\mathrm{Y}}}{\overline{\mathrm{X}}+\beta_{1}}$ \\
\hline $\begin{array}{l}\widehat{\mathrm{Y}}_{11}=\frac{\overline{\mathrm{y}}+\mathrm{b}(\overline{\mathrm{X}}-\overline{\mathrm{x}})}{\left(\overline{\mathrm{x}} \beta_{1}+\beta_{2}\right)}\left(\overline{\mathrm{X}} \beta_{1}+\beta_{2}\right) \\
\text { Yan and Tian [15] }\end{array}$ & $\frac{(1-f)}{n} \frac{S_{x}^{2}}{\bar{Y}} R_{11}^{2}$ & $\frac{(1-f)}{n}\left(R_{11}^{2} S_{x}^{2}+S_{y}^{2}\left(1-\rho^{2}\right)\right)$ & $\mathrm{R}_{11}=\frac{\overline{\mathrm{Y}} \beta_{1}}{\overline{\mathrm{X}} \beta_{1}+\beta_{2}}$ \\
\hline $\begin{array}{l}\widehat{\mathrm{Y}}_{12}=\frac{\overline{\mathrm{y}}+\mathrm{b}(\overline{\mathrm{X}}-\overline{\mathrm{x}})}{(\overline{\mathrm{x}}+\rho)}(\overline{\mathrm{X}}+\rho) \\
\text { Kadilar and Cingi [3] }\end{array}$ & $\frac{(1-f)}{n} \frac{S_{x}^{2}}{\bar{Y}} R_{12}^{2}$ & $\frac{(1-f)}{n}\left(R_{12}^{2} S_{x}^{2}+S_{y}^{2}\left(1-\rho^{2}\right)\right)$ & $R_{12}=\frac{\bar{Y}}{\bar{X}+\rho}$ \\
\hline $\begin{array}{l}\widehat{\mathrm{Y}}_{13}=\frac{\overline{\mathrm{y}}+\mathrm{b}(\overline{\mathrm{X}}-\overline{\mathrm{x}})}{\left(\overline{\mathrm{x}} \mathrm{C}_{\mathrm{x}}+\rho\right)}\left(\overline{\mathrm{X}} \mathrm{C}_{\mathrm{x}}+\rho\right) \\
\text { Kadilar and Cingi [3] }\end{array}$ & $\frac{(1-f)}{n} \frac{S_{x}^{2}}{\bar{Y}} R_{13}^{2}$ & $\frac{(1-f)}{n}\left(R_{13}^{2} S_{x}^{2}+S_{y}^{2}\left(1-\rho^{2}\right)\right)$ & $\mathrm{R}_{13}=\frac{\overline{\mathrm{Y}} \mathrm{C}_{\mathrm{x}}}{\overline{\mathrm{X}} \mathrm{C}_{\mathrm{x}}+\rho}$ \\
\hline $\begin{array}{l}\widehat{\overline{\mathrm{Y}}}_{14}=\frac{\overline{\mathrm{y}}+\mathrm{b}(\overline{\mathrm{X}}-\overline{\mathrm{x}})}{\left(\overline{\mathrm{x}} \rho+\mathrm{C}_{\mathrm{x}}\right)}\left(\overline{\mathrm{X}} \rho+\mathrm{C}_{\mathrm{x}}\right) \\
\text { Kadilar and Cingi [3] }\end{array}$ & $\frac{(1-f)}{n} \frac{S_{x}^{2}}{\bar{Y}} R_{14}^{2}$ & $\frac{(1-f)}{n}\left(R_{14}^{2} S_{x}^{2}+S_{y}^{2}\left(1-\rho^{2}\right)\right)$ & $\mathrm{R}_{14}=\frac{\overline{\mathrm{Y}} \rho}{\overline{\mathrm{X}} \rho+\mathrm{C}_{\mathrm{x}}}$ \\
\hline $\begin{array}{l}\widehat{\mathrm{Y}}_{15}=\frac{\overline{\mathrm{y}}+\mathrm{b}(\overline{\mathrm{X}}-\overline{\mathrm{x}})}{\left(\overline{\mathrm{x}} \rho+\beta_{2}\right)}\left(\overline{\mathrm{X}} \rho+\beta_{2}\right) \\
\text { Kadilar and Cingi [3] }\end{array}$ & $\frac{(1-f)}{n} \frac{S_{x}^{2}}{\bar{Y}} R_{15}^{2}$ & $\frac{(1-f)}{n}\left(R_{15}^{2} S_{x}^{2}+S_{y}^{2}\left(1-\rho^{2}\right)\right)$ & $\mathrm{R}_{15}=\frac{\overline{\mathrm{Y}} \rho}{\overline{\mathrm{X}} \rho+\beta_{2}}$ \\
\hline
\end{tabular}


The modified ratio estimators discussed above are biased but have minimum mean squared errors compared to the usual ratio estimator. The list of estimators given in Table 1.1 uses the known values of the parameters like $\bar{X}, C_{x}, \beta_{1}, \beta_{2}, \rho$ and their linear combinations. However it seems, there is no attempt is made to use the known value of the population median $\mathrm{M}_{\mathrm{d}}$ of the auxiliary variable to improve the ratio estimators. Further we know that the value of median is unaffected and robustness by the extreme values or the presence of outliers in the population values unlike the other parameters like the mean, coefficient of variation, coefficient of skewness and coefficient of kurtosis etc. These points, discussed above have motivated us to introduce a modified ratio estimator using the known value of the population median of the auxiliary variable. As a result, it is observed that the proposed estimator performs better than the usual ratio estimator as well as the existing modified ratio estimators listed in Table 1.1. The materials of the present study are arranged as given below. The proposed modified ratio estimator with known population median is presented in section 2 where as the conditions in which the proposed estimator performs better than the existing modified ratio estimators are derived in section 3. The performances of the proposed modified ratio estimator and the existing modified ratio estimators are assessed for certain natural populations in section 4 and the conclusion is presented in section 5 .

\section{Proposed Modified Ratio Estimator with Known Median}

As we stated earlier one can always improve the performance of the estimator of the study variable by using the known population parameters of the auxiliary variable, which are positively correlated with that of study variable. In this section we have suggested a modified ratio estimator using the population median of the auxiliary variable.

The proposed modified ratio estimator for population mean $\bar{Y}$ is defined as

$$
\widehat{\bar{Y}}_{p}=\bar{y}\left[\frac{\bar{x}+M_{d}}{\bar{x}+M_{d}}\right]
$$

where $M_{d}$ is the population median of the auxiliary variable $X$.

The bias and mean squared error of $\widehat{\bar{Y}}_{p}$ to the first degree of approximation are derived as given below:

$$
\begin{aligned}
& B\left(\widehat{\bar{Y}}_{p}\right)=\frac{(1-f)}{n} \bar{Y}\left(\theta_{p}^{2} C_{x}^{2}-\theta_{p} C_{x} C_{y} \rho\right) \\
& \operatorname{MSE}\left(\widehat{\bar{Y}}_{p}\right)=\frac{(1-f)}{n} \bar{Y}^{2}\left(C_{y}^{2}+\theta_{p}^{2} C_{x}^{2}-2 \theta_{p} C_{x} C_{y} \rho \text { where } \theta_{p}=\frac{\bar{x}}{\bar{X}+M_{d}}\right.
\end{aligned}
$$

\section{Comparison of Proposed Estimator with Existing Modified Ratio Estimators}

For want of space; for the sake of convenience to the readers and for the ease of comparisons, the modified ratio estimators given in Table 1.1 are classified into two classes; the first 5 modified ratio estimators is classified as class 1 and the remaining 10 modified ratio estimators as class 2 as given below: 


\section{Class 1:}

The biases, the mean squared errors and the constants of the first 5 modified ratio estimators $\widehat{\bar{Y}}_{1}$ to $\widehat{\bar{Y}}_{5}$ listed in the Table 1.1 are classified into a single class (say, Class 1), which will be very much useful for comparing with that of proposed modified ratio estimator and are given below:

$$
\begin{aligned}
& B\left(\widehat{\bar{Y}}_{i}\right)=\frac{(1-f)}{n} \bar{Y}\left(\theta_{i}^{2} C_{x}^{2}-\theta_{i} C_{x} C_{y} \rho\right) \\
& \operatorname{MSE}\left(\widehat{Y}_{i}\right)=\frac{(1-f)}{n} \bar{Y}^{2}\left(C_{y}^{2}+\theta_{i}^{2} C_{x}^{2}-2 \theta_{i} C_{x} C_{y} \rho\right) i=1,2,3,4 \text { and } 5
\end{aligned}
$$

where $\theta_{1}=\frac{\bar{x}}{\overline{\mathrm{X}}+\mathrm{C}_{\mathrm{x}}}, \theta_{2}=\frac{\overline{\mathrm{X}}}{\overline{\mathrm{X}}+\beta_{2}}, \theta_{3}=\frac{\overline{\mathrm{x}}}{\overline{\mathrm{X}}+\beta_{1}}, \theta_{4}=\frac{\overline{\mathrm{x}}}{\overline{\mathrm{X}}+\rho}$ and $\theta_{5}=\frac{\overline{\mathrm{x}} \mathrm{C}_{\mathrm{x}}}{\overline{\mathrm{x}} \mathrm{C}_{\mathrm{x}}+\beta_{2}}$

\section{Class 2:}

The biases, the mean squared errors and the constants of the remaining 10 modified ratio estimators $\widehat{\bar{Y}}_{6}$ to $\widehat{\bar{Y}}_{15}$ listed in the Table 1.1 are classified into a single class (say, Class 2), which will be very much useful for comparing with that of proposed modified ratio estimator and are given below:

$$
\begin{aligned}
& B\left(\widehat{\widehat{Y}}_{i}\right)=\frac{(1-f)}{n} \frac{S_{x}^{2}}{\bar{Y}} R_{i}^{2} \\
& \operatorname{MSE}\left(\widehat{\bar{Y}}_{i}\right)=\frac{(1-f)}{n}\left(R_{i}^{2} S_{x}^{2}+S_{y}^{2}\left(1-\rho^{2}\right)\right) i=6,7,8,9,10,11,12,13,14 \text { and } 15
\end{aligned}
$$

where

$$
\begin{aligned}
& R_{6}=\frac{\bar{Y}}{\bar{X}}, R_{7}=\frac{\bar{Y}}{\bar{X}+C_{x}}, R_{8}=\frac{\bar{Y}}{\bar{X}+\beta_{2}}, R_{9}=\frac{\bar{Y} C_{x}}{\bar{X} C_{x}+\beta_{2}}, R_{10}=\frac{\bar{Y}}{\bar{X}+\beta_{1}}, R_{11}=\frac{\bar{Y} \beta_{1}}{\bar{X} \beta_{1}+\beta_{2}}, \\
& R_{12}=\frac{\bar{Y}}{\bar{X}+\rho}, R_{13}=\frac{\bar{Y} C_{x}}{\bar{X} C_{x}+\rho}, R_{14}=\frac{\bar{Y} \rho}{\bar{X} \rho+C_{x}} \text { and } R_{15}=\frac{\bar{Y} \rho}{\bar{X} \rho+\beta_{2}}
\end{aligned}
$$

The bias and mean squared error of the proposed modified ratio estimator are given below:

$$
\begin{aligned}
& B\left(\widehat{\bar{Y}}_{p}\right)=\frac{(1-f)}{n} \bar{Y}\left(\theta_{p}^{2} C_{x}^{2}-\theta_{p} C_{x} C_{y} \rho\right) \\
& \operatorname{MSE}\left(\widehat{Y}_{p}\right)=\frac{(1-f)}{n} \bar{Y}^{2}\left(C_{y}^{2}+\theta_{p}^{2} C_{x}^{2}-2 \theta_{p} C_{x} C_{y} \rho\right)
\end{aligned}
$$

where $f=\frac{\mathrm{n}}{\mathrm{N}}$ and $\theta_{\mathrm{p}}=\frac{\overline{\mathrm{x}}}{\overline{\mathrm{X}}+\mathrm{M}_{\mathrm{d}}}$

From the expressions given in (3.1) and (3.3) we have derived the conditions for which the proposed estimator $\hat{\bar{Y}}_{p}$ is more efficient than the existing modified ratio estimators given in Class $1, \widehat{\bar{Y}}_{\mathrm{i}} ; \mathrm{i}=1,2,3,4$ and 5 and are given below.

That is, $\operatorname{MSE}\left(\widehat{\mathrm{Y}}_{\mathrm{p}}\right)<\operatorname{MSE}\left(\widehat{\mathrm{Y}}_{\mathrm{i}}\right)$

if $\quad \rho<\frac{\left(\theta_{\mathrm{p}}+\theta_{\mathrm{i}}\right)}{2} \frac{\mathrm{C}_{\mathrm{x}}}{\mathrm{C}_{\mathrm{y}}} ; \mathrm{i}=1,2,3,4$ and 5 
From the expressions given in (3.2) and (3.3) we have derived the conditions for which the proposed estimator $\hat{\bar{Y}}_{p}$ is more efficient than the existing modified ratio estimators given in Class $2, \widehat{\mathrm{Y}}_{\mathrm{i}} ; \mathrm{i}=6,7,8,9,10,11,12,13,14$ and 15 and are given below.

That is, $\operatorname{MSE}\left(\widehat{\mathrm{Y}}_{\mathrm{p}}\right)<\operatorname{MSE}\left(\widehat{\mathrm{Y}}_{\mathrm{i}}\right)$

if $\frac{\theta_{\mathrm{p}} \mathrm{C}_{\mathrm{x}}-\mathrm{R}_{\mathrm{i}}^{*} \mathrm{~S}_{\mathrm{x}}}{\mathrm{C}_{\mathrm{y}}}<\rho<\frac{\mathrm{R}_{\mathrm{i}}^{*} \mathrm{~S}_{\mathrm{x}}+\theta_{\mathrm{p}} \mathrm{C}_{\mathrm{x}}}{\mathrm{C}_{\mathrm{y}}}$

or $\frac{\mathrm{R}_{\mathrm{i}}^{*} \mathrm{~S}_{\mathrm{x}}+\theta_{\mathrm{p}} \mathrm{C}_{\mathrm{x}}}{\mathrm{C}_{\mathrm{y}}}<\rho<\frac{\theta_{\mathrm{p}} \mathrm{C}_{\mathrm{x}}-\mathrm{R}_{\mathrm{i}}^{*} \mathrm{~S}_{\mathrm{x}}}{\mathrm{C}_{\mathrm{y}}} \mathrm{i}=6,7,8,9,10,11,12,13,14$ and 15

where $R_{i}^{*}=\frac{R_{i}}{\bar{Y}}$

\section{Empirical Study}

The performance of the proposed modified ratio estimator is assessed with that of existing modified ratio estimators listed in Table 1.1 for certain natural populations. The populations 1 and 2 are taken from Murthy [1] in page 228 and population 3 is taken from Cochran [2] in page 325. The population parameters and the constants obtained from the above populations are given below:

\section{Population-1: Murthy [1]}

$\mathrm{X}=$ Fixed Capital and $\mathrm{Y}=$ Output for 80 factories in a region

$$
\begin{array}{llll}
\mathrm{N}=80 & \mathrm{n}=20 & \overline{\mathrm{Y}}=51.8264 & \overline{\mathrm{X}}=11.2646 \\
\rho=0.9413 & \mathrm{~S}_{\mathrm{y}}=18.3569 & \mathrm{C}_{\mathrm{y}}=0.3542 & \mathrm{~S}_{\mathrm{x}}=8.4563 \\
\mathrm{C}_{\mathrm{x}}=0.7507 & \beta_{2}=-0.06339 & \beta_{1}=1.05 & \mathrm{M}_{\mathrm{d}}=7.575
\end{array}
$$

\section{Population-2: Murthy [1]}

$\mathrm{X}=$ Data on number of workers and $\mathrm{Y}=$ Output for 80 factories in a region

$$
\begin{array}{llll}
\mathrm{N}=80 & \mathrm{n}=20 & \overline{\mathrm{Y}}=51.8264 & \overline{\mathrm{X}}=2.8513 \\
\rho=0.9150 & \mathrm{~S}_{\mathrm{y}}=18.3569 & \mathrm{C}_{\mathrm{y}}=0.3542 & \mathrm{~S}_{\mathrm{x}}=2.7042 \\
\mathrm{C}_{\mathrm{x}}=0.9484 & \beta_{2}=1.3005 & \beta_{1}=0.6978 & \mathrm{M}_{\mathrm{d}}=1.48
\end{array}
$$

\section{Population-3: Cochran [2]}

$\mathrm{X}=$ Number of rooms and $\mathrm{Y}=$ Number of persons

$$
\begin{array}{llll}
\mathrm{N}=10 & \mathrm{n}=4 & \overline{\mathrm{Y}}=101.1 & \overline{\mathrm{X}}=58.8 \\
\rho=0.6515 & \mathrm{~S}_{\mathrm{y}}=14.6523 & \mathrm{C}_{\mathrm{y}}=0.1449 & \mathrm{~S}_{\mathrm{x}}=7.5339 \\
\mathrm{C}_{\mathrm{x}}=0.1281 & \beta_{2}=-0.3814 & \beta_{1}=0.5764 & \mathrm{M}_{\mathrm{d}}=58
\end{array}
$$

The biases, mean squared errors, constants and the ratio of mean squared errors of the existing and proposed modified ratio estimators for the populations given above are given in the following Tables: 
Table 4.1: Biases of the existing and proposed modified ratio estimators

\begin{tabular}{|l|c|c|c|}
\hline \multirow{2}{*}{ Estimator } & \multicolumn{3}{|c|}{ Bias } \\
\cline { 2 - 4 } & Population 1 & Population 2 & Population 3 \\
\hline$\widehat{\mathrm{Y}}_{1}$ Sisodia and Dwivedi [13] & 0.5066 & 0.5360 & 0.0647 \\
\hline$\widehat{\mathrm{Y}}_{2}$ Singh et.al [11] & 0.6184 & 0.4142 & 0.0675 \\
\hline$\widehat{\mathrm{Y}}_{3}$ Yan and Tian [15] & 0.4714 & 0.6483 & 0.0624 \\
\hline$\widehat{\widehat{Y}}_{4}$ Singh and Tailor [10] & 0.4839 & 0.5496 & 0.0620 \\
\hline$\widehat{\mathrm{Y}}_{5}$ Upadhyaya and Singh [14] & 0.6217 & 0.3937 & 0.0829 \\
\hline$\widehat{\mathrm{Y}}_{6}$ Kadilar and Cingi [2] & 1.0952 & 1.7481 & 0.2489 \\
\hline$\widehat{\widehat{Y}}_{7}$ Kadilar and Cingi [2] & 0.9626 & 0.9843 & 0.2478 \\
\hline$\widehat{\widehat{Y}}_{8}$ Kadilar and Cingi [2] & 1.1076 & 0.8244 & 0.2522 \\
\hline$\widehat{\mathrm{Y}}_{9}$ Kadilar and Cingi [2] & 1.1118 & 0.7970 & 0.2762 \\
\hline$\widehat{\bar{Y}}_{10}$ Yan and Tian [15] & 0.9164 & 1.1282 & 0.2441 \\
\hline$\widehat{\widehat{Y}}_{11}$ Yan and Tian [15] & 1.1070 & 0.6392 & 0.2546 \\
\hline$\widehat{\mathrm{Y}}_{12}$ Kadilar and Cingi [3] & 0.9328 & 1.0011 & 0.2435 \\
\hline$\widehat{\mathrm{Y}}_{13}$ Kadilar and Cingi [3] & 0.8868 & 0.9759 & 0.2108 \\
\hline$\widehat{\widehat{Y}}_{14}$ Kadilar and Cingi [3] & 0.9552 & 0.9402 & 0.2473 \\
\hline$\widehat{\mathrm{Y}}_{15}$ Kadilar and Cingi [3] & 1.1084 & 0.7785 & 0.2539 \\
\hline$\widehat{\mathrm{Y}}_{\mathrm{p}}$ (Proposed estimator) & 0.1007 & 0.3643 & 0.0293 \\
\hline
\end{tabular}

Table 4.2: $\quad$ The mean squared errors and constants of the existing and proposed modified ratio estimators

\begin{tabular}{|l|r|r|r|r|r|r|}
\hline \multirow{2}{*}{ Estimator } & \multicolumn{2}{|c|}{ Population 1 } & \multicolumn{2}{c|}{ Population 2 } & \multicolumn{2}{c|}{ Population 3 } \\
\cline { 2 - 7 } & MSE & $\begin{array}{c}\text { Constants } \\
\boldsymbol{\theta}_{\boldsymbol{i}} \text { or } \boldsymbol{R}_{\boldsymbol{i}}\end{array}$ & MSE & $\begin{array}{c}\text { Constants } \\
\boldsymbol{\theta}_{\boldsymbol{i}} \text { or } \boldsymbol{R}_{\boldsymbol{i}}\end{array}$ & MSE & $\begin{array}{c}\text { Constants } \\
\boldsymbol{\theta}_{\boldsymbol{i}} \text { or } \boldsymbol{R}_{\boldsymbol{i}}\end{array}$ \\
\hline$\widehat{\mathrm{Y}}_{1}$ Sisodia and Dwivedi [13] & 15.2581 & 0.9375 & 17.1881 & 0.7504 & 20.2396 & 0.9978 \\
\hline$\widehat{\mathrm{Y}}_{2}$ Singh et.al [11] & 19.3382 & 1.0057 & 12.8426 & 0.6868 & 20.3557 & 1.0065 \\
\hline$\widehat{\bar{Y}}_{3}$ Yan and Tian [15] & 14.0113 & 0.9147 & 21.3660 & 0.8034 & 20.1421 & 0.9902 \\
\hline$\widehat{\mathrm{Y}}_{4}$ Singh and Tailor [10] & 14.4503 & 0.9229 & 17.6849 & 0.7571 & 20.1262 & 0.9890 \\
\hline$\widehat{\mathrm{Y}}_{5}$ Upadhyaya and Singh [14] & 19.4592 & 1.0076 & 12.1351 & 0.6752 & 21.0458 & 1.0533 \\
\hline$\widehat{\mathrm{Y}}_{6}$ Kadilar and Cingi [2] & 58.2026 & 4.6008 & 92.6562 & 18.1764 & 43.7043 & 1.7193 \\
\hline$\widehat{\mathrm{Y}}_{7}$ Kadilar and Cingi [2] & 51.3313 & 4.3133 & 53.0736 & 13.6396 & 43.5950 & 1.7156 \\
\hline$\widehat{\mathrm{Y}}_{8}$ Kadilar and Cingi [2] & 58.8469 & 4.6268 & 44.7874 & 12.4829 & 44.0341 & 1.7306 \\
\hline$\widehat{\mathrm{Y}}_{9}$ Kadilar and Cingi [2] & 59.0633 & 4.6355 & 43.3674 & 12.2737 & 46.4608 & 1.8110 \\
\hline$\widehat{\mathrm{Y}}_{10}$ Yan and Tian [15] & 48.9356 & 4.2085 & 60.5324 & 14.6027 & 43.2180 & 1.7026 \\
\hline$\widehat{\mathrm{Y}}_{11}$ Yan and Tian [15] & 58.8159 & 4.6256 & 35.1887 & 10.9918 & 44.2805 & 1.7389 \\
\hline$\widehat{\mathrm{Y}}_{12}$ Kadilar and Cingi [3] & 49.7853 & 4.2460 & 53.9825 & 13.7606 & 43.1557 & 1.7005 \\
\hline$\widehat{\mathrm{Y}}_{13}$ Kadilar and Cingi [3] & 47.4010 & 4.1399 & 52.6365 & 13.5810 & 39.8564 & 1.5825 \\
\hline$\widehat{\widehat{Y}}_{14}$ Kadilar and Cingi [3] & 50.9447 & 4.2966 & 50.7876 & 13.3305 & 43.5368 & 1.7136 \\
\hline$\widehat{\widehat{Y}}_{15}$ Kadilar and Cingi [3] & 58.8874 & 4.6285 & 42.4051 & 12.1299 & 44.2131 & 1.7366 \\
\hline$\widehat{\mathrm{Y}}_{p}$ (Proposed estimator) & 2.7825 & 0.5979 & 11.1365 & 0.6583 & 19.8992 & 0.5034 \\
\hline
\end{tabular}


Table 4.3: Comparison of the proposed and the existing modified ratio estimators

\begin{tabular}{|c|c|c|c|}
\hline \multirow[t]{2}{*}{ Estimator } & \multicolumn{3}{|c|}{ Efficiency $e\left(\widehat{\bar{Y}}_{i}, \widehat{\bar{Y}}_{p}\right)=\frac{\operatorname{MSE}\left(\widehat{\widehat{Y}}_{i}\right)}{\operatorname{MSE}\left(\widehat{\widehat{Y}}_{p}\right)}$} \\
\hline & Population 1 & Population 2 & Population 3 \\
\hline$\widehat{\bar{Y}}_{1}$ Sisodia and Dwivedi [13] & 5.4836 & 1.5434 & 1.0171 \\
\hline$\widehat{\widehat{Y}}_{2}$ Singh et.al $[11]$ & 6.9499 & 1.1532 & 1.0229 \\
\hline$\widehat{\bar{Y}}_{3}$ Yan and Tian [15] & 5.0355 & 1.9186 & 1.0122 \\
\hline$\widehat{\widehat{Y}}_{4}$ Singh and Tailor [10] & 5.1933 & 1.5880 & 1.0114 \\
\hline$\widehat{\widehat{Y}}_{5}$ Upadhyaya and Singh [14] & 6.9934 & 1.0897 & 1.0576 \\
\hline$\widehat{\overline{\mathrm{Y}}}_{6}$ Kadilar and Cingi $[2]$ & 20.9174 & 8.3200 & 2.1963 \\
\hline$\widehat{\widehat{\mathrm{Y}}}_{7}$ Kadilar and Cingi [2] & 18.4479 & 4.7657 & 2.1908 \\
\hline$\widehat{\bar{Y}}_{8}$ Kadilar and Cingi [2] & 21.1489 & 4.0217 & 2.2129 \\
\hline$\widehat{\widehat{Y}}_{9}$ Kadilar and Cingi [2] & 21.2267 & 3.8942 & 2.3348 \\
\hline$\widehat{\widehat{Y}}_{10}$ Yan and Tian [15] & 17.5869 & 5.4355 & 2.1718 \\
\hline$\widehat{\widehat{Y}}_{11}$ Yan and Tian [15] & 21.1378 & 3.1598 & 2.2252 \\
\hline$\widehat{\bar{Y}}_{12}$ Kadilar and Cingi [3] & 17.8923 & 4.8473 & 2.1687 \\
\hline$\widehat{\bar{Y}}_{13}$ Kadilar and Cingi [3] & 17.0354 & 4.7265 & 2.0029 \\
\hline$\widehat{\widehat{Y}}_{14}$ Kadilar and Cingi [3] & 18.3090 & 4.5605 & 2.1879 \\
\hline$\widehat{\widehat{Y}}_{15}$ Kadilar and Cingi [3] & 21.1635 & 3.8078 & 2.2219 \\
\hline
\end{tabular}

From the values of Table 4.1, it is observed that the bias of the proposed ratio estimator is less than the biases of all the 15 existing modified ratio estimators. Similarly from the values of Table 4.2, it is observed that the mean squared error of the proposed modified ratio estimator is less than the mean squared errors of all the 15 existing modified ratio estimators. For the sake of convenience to the readers the ratio of the mean squared errors of the existing modified ratio estimators $\widehat{\bar{Y}}_{i}(i=1,2,3 \ldots 15)$ to that of proposed modified ratio estimator $\widehat{\bar{Y}}_{\mathrm{p}}$ are presented in Table 4.3. From the table values it is observed that the proposed modified ratio estimator is performed better than the existing estimators. In fact the ratio of mean squared errors varies from 5.0355 to 21.2267 for the population 1, from 1.0897 to 8.3200 for the population 2 and from 1.0114 to 2.3348 for the population 3 .

\section{Conclusion}

The ratio estimator is used to improve the performance of the estimator based on simple random sample without replacement, whenever there is an auxiliary variable which is positively correlated with that of the study variable and its parameters are known. In this paper a modified ratio estimator has been suggested using the population median of the auxiliary variable. The bias and mean squared error of the proposed modified ratio estimator are obtained and compared with that of existing modified ratio estimators. It is observed that the bias and mean squared error of the proposed estimator are less than the biases and mean squared errors of all the existing modified ratio estimators for certain known populations. 


\section{Acknowledgement}

The second author wishes to record his gratitude and thanks to the Vice Chancellor, Pondicherry University and other University authorities for having given the financial assistance to carry out this research work through the University Fellowship.

\section{References}

1. Cochran, W. G. (1977). Sampling Techniques, Third Edition, Wiley Eastern Limited.

2. Kadilar, C. and Cingi, H. (2004). Ratio estimators in simple random sampling, Applied Mathematics and Computation 151, 893-902.

3. Kadilar, C. and Cingi, H. (2006). An Improvement in Estimating the Population mean by using the Correlation Coefficient, Hacettepe Journal of Mathematics and Statistics Volume 35 (1), 103-109.

4. Koyuncu, N. and Kadilar, C. (2009). Efficient Estimators for the Population mean, Hacettepe Journal of Mathematics and Statistics, Volume 38(2), 217-225.

5. Murthy, M.N. (1967). Sampling theory and methods, Statistical Publishing Society, Calcutta, India.

6. Prasad, B. (1989). Some improved ratio type estimators of population mean and ratio in finite population sample surveys, Communications in Statistics: Theory and Methods 18, 379-392,

7. Rao, T.J. (1991). On certain methods of improving ratio and regression estimators, Communications in Statistics: Theory and Methods 20 (10), 3325-3340.

8. Singh, D. and Chaudhary, F.S. (1986). Theory and Analysis of Sample Survey Designs, New Age International Publisher.

9. Singh, G.N. (2003). On the improvement of product method of estimation in sample surveys, Journal of the Indian Society of Agricultural Statistics 56 (3), 267-265.

10. Singh, H.P. and Tailor, R. (2003). Use of known correlation coefficient in estimating the finite population means, Statistics in Transition 6 (4), 555-560.

11. Singh, H.P., Tailor, R., Tailor, R. and Kakran, M.S. (2004). An Improved Estimator of population mean using Power transformation, Journal of the Indian Society of Agricultural Statistics 58(2), 223-230.

12. Singh, H.P. and Tailor, R. (2005). Estimation of finite population mean with known coefficient of variation of an auxiliary, STATISTICA, anno LXV, n.3, pp 301-31.

13. Sisodia, B.V.S. and Dwivedi, V.K. (1981). A modified ratio estimator using coefficient of variation of auxiliary variable, Journal of the Indian Society of Agricultural Statistics 33(1), 13-18.

14. Upadhyaya, L.N. and Singh, H.P. (1999). Use of transformed auxiliary variable in estimating the finite population mean, Biometrical Journal 41 (5), 627-636.

15. Yan, Z. and Tian, B. (2010). Ratio Method to the Mean Estimation Using Coefficient of Skewness of Auxiliary Variable, ICICA 2010, Part II, CCIS 106, pp. $103-110$. 